\title{
Hypertension Exercise Videos Reduce Blood Pressure of Hypertension Patients
}

\author{
Harmilah Harmilah*, Bondan Palestin, Ana Ratnawati, Agus Sarwo Prayogi, Catur Budi Susilo \\ Department of Nursing, Polytechnic Ministry of Health, Yogyakarta, Indonesia
}

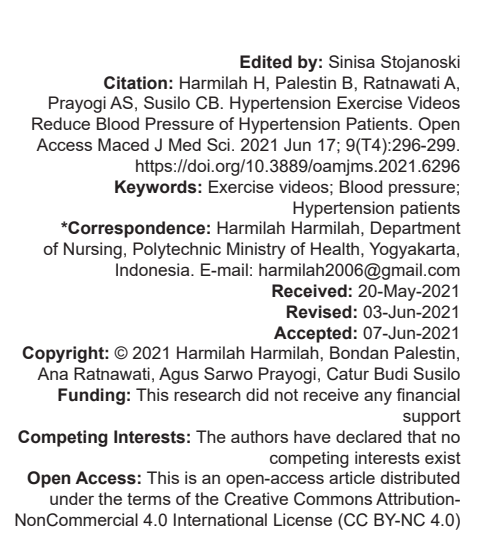

\begin{abstract}
BACKGROUND: Hypertension is a symptom of a cardiovascular degenerative disease that is mostly experienced by the elderly and cause is not certain. However, the reduction of blood pressure (BP) with drugs and nondrugs can reduce damage to target organs and prevent cardiovascular diseases.

AIM: the study identified the effect of hypertension exercise videos of lowering BP.

METHODS: The type of research that has been used is quasi-experimental with pre-test and post-test design with control group. The sampling technique used was random sampling, the number of samples was 30 samples which were the treatment group and 30 samples were control the control group. The data analysis used was the t-test and Wilcoxon and Mann-Whitney test.

RESULTS: The mean reduction in systolic BP in respondents who did exercise was $13.67 \mathrm{~mm} \mathrm{Hg}$ with a standard deviation of 10.57, while the mean in systolic BP in respondents who did not exercise was $0.50 \mathrm{mmHg}$ a pressure were 40.95 in the group of respondents who did hypertension exercise with $p=0.000$. This means that there is significant difference, in the mean reduction in systolic and diastolic BP between respondents those who do exercise.

CONCLUSION: Hypertension exercise video reduces BP of hypertension patients.
\end{abstract}

\section{Introduction}

Hypertension is a symptom of a cardiovascular degenerative disease that is mostly experienced by the elderly and the cause is not certain. Hypertension is the most common risk factor for cardiovascular disease leading to death. However, lowering blood pressure (BP) by drugs and non-drug and non-pharmaceutical methods will reduce damage to target organs and prevents cardiovascular diseases [1].

Hypertension is a major contributor to short life expectancy for African Americans. Lifestyle changes as an intervention cannot yet be developed, especially for young African American men. Hypertension in society requires lifestyle changes as a form of developing education and knowledge about hypertension [2].

The prevalence of hypertension measured by $\mathrm{BP}$ has increased from $25.8 \%$ to $34.1 \%$. The increase in prevalence of hypertension is related to lifestyle, including smoking, consumption of alcoholic drinks, physical activity, and consumption of fruits and vegetables [3].

In adult, a $20 \mathrm{mmHg}$ increase in systolic BP results in a $60 \%$ increase in the risk of death cause by cardiovascular disease. It is estimated that about $80 \%$ of the increase in cases of hypertension, especially in developing countries in 2025 from a total of 639 million cases in 2000, is estimated to be 1.15 billion cases in 2025 [4].

Hypertension is a health problem that often occurs in society. Uncontrolled hypertension can lead to degenerative disease, such as congestive heart failure, and vascular disease. Hypertension is called the "silent killer" because it is asymptomatic and after several years leads to fatal strokes or heart disease. Although it cannot be treated, prevention and management can reduce the incidence of hypertension, and its accompanying diseases [5].

$$
\text { Handling/treating hypertension, }
$$
respondents must have adherence to control effectively and receive regular multiple interventions both drugs and other alternatives [4], [6]. The use traditional medicines in hypertension and related diseases can lead to poor outcomes, associated with delays in seeking appropriate treatment, leading to increased disease severity or complication, drug interactions, and adherence to allopathic drugs known to control the disease [4], [7].

Hypertension cannot be treated, but preventive and management measures can be taken such as providing health education to reduce the 
number of cases of hypertension and the disease that accompany it. Effort made to prevent hypertension and reducing salt consumption; consuming foods containing potassium, magnesium and calcium; reducing drinking or alcoholic foods; regular exercise; eat high-fiber vegetables and fruits; reduce stress; stop smoking; controlling cholesterol level; and controlling diabetes. Therefore, families who have a history of hypertension must get sufficient knowledge about hypertension and the right action to lower BP. If not treated seriously, hypertension can cause serious complications, including heart infarction, heart failure, stroke, and chronic kidney failure [8]. The most easily handled non-pharmacological hypertension for families is reflexology [9]. In study, it explained that there were significant differences in systolic and diastolic BP before and after given intradialitic exercise [10], [11].

A preliminary study conduct few months before the study through interviews with ten people with hypertension showed that seven people with hypertension had never done exercise or physical exercise. The other three people have done exercise, but they do not do it all now because the feel that they are doing physical exercises such as doing household chores. Based on the explanation above, the researcher wanted to find out whether the hypertension exercise video could lower BP among people with hypertension. The research objective is a hypertension exercise video that has an effect on reducing BP.

\section{Methods}

The research design used was quasiexperimental pre-post-test with control group. The study was conducted for 12 weeks (3 months). Sampling technique is random sampling, with sample of 30 experimental groups and 30 control groups. Before being given the treatment and after being given the hypertension gymnastic treatment, BP measurements were taken both in the experimental group and in the control group (on the $1^{\text {st }}$ week and at the $12^{\text {th }}$ week). The experimental group was guided to do hypertensive exercise for 30 min 3 times a week and exercise for 12 weeks. Meanwhile, the control group did the exercise once per week, as usual the respondents had done. Data analysis used was t-test, Wilcoxon, and Mann-Whitney.

\section{Results}

The mean age of the respondents who participated in exercise was 51.52 years $(95 \% \mathrm{Cl}$ : $-2.52-3.36)$, with a standard deviation of 6.80 . The youngest is 40 years old and the oldest is 61 years. Meanwhile, the mean of respondents who did not participate in exercise hypertension was 51.2 years, with a standard deviation of 4.29. The youngest was 43 years old and the oldest was 58 years old. More details are shown in Table 1.

Table 1: Distribution frequency age of respondents characteristic

\begin{tabular}{llll}
\hline Group & Mean & SD & $95 \% \mathrm{Cl}$ \\
\hline Intervention & 51.53 & 6.81 & $2.51-3.37$ \\
Control & 51.1 & 4.29 & $2.52-3.39$ \\
\hline
\end{tabular}

Based on the data, it was found that the majority of respondents who experience hypertension were female 30 peoples (55\%), with the majority of high school education levels were 18 peoples (60\%), and nearly half of the respondents had hypertension for $<1$ years around 27 (48\%). More results are given in Table 2.

Before statistical analysis, an assumption test or normality test is carried out. Based on the results of the normality distributed, systolic BP results in the exercise group, diastolic BP in both the intervention group and control, while the data that were not normally distributed were the diastolic pressure data in the control group.

Based on Table 2, it shows that it shows that the systolic BP variable of hypertension respondents in both the intervention group and the control group is $p>0.05$, so it can be concluded that the systolic BP data of hypertension respondents are normally distributed. The diastolic BP variable in the control group $p>0.05$ means that it is normally distributed, while the diastolic $\mathrm{BP}$ in the intervention group $\mathrm{p}<0.05$ means that the data are not normally distributed. The data were not normally distributed analyzed using Wilcoxon and Mann-Whitney.

Table 2: Distribution of respondents, by gender, education, and length of living with hypertension

\begin{tabular}{lll}
\hline Characteristic & Group & \\
\cline { 2 - 3 } & Intervention Frequency (\%) & Control Frequency (\%) \\
\hline Gender & 83.3 & 33.3 \\
$\quad$ Female & 16.7 & 66.7 \\
$\quad$ Male & & \\
Education & 23.33 & 10.0 \\
$\quad$ Elementary & 46.7 & 35.0 \\
Junior & 30.0 & 46.7 \\
Senior & 0.0 & 8.3 \\
University & & \\
Length of hypertension & 38.5 & 56.7 \\
0-1 year & 34.6 & 30.0 \\
2-3 years & 19.2 & 10.0 \\
4-5 years & 0.0 & 3.3 \\
6-7 years & 7.7 & 0.0 \\
10-11 years & & \\
\hline
\end{tabular}

Based on analysis in Table 3, it showed that there was significant difference in the mean of systolic BP of respondents who did hypertension group with $p=0.02$, while in the control group there is no difference in the mean systolic BP at week 1 with week 12 , with $p=0.81$.

Based on Table 4, it showed that there is difference in the Mean Ranks of distolic BP at week I and week XII both for intervention group and control group with $p=0.000$ for intervention group and $p=0.048$ for control group. 
Table 3: Mean of respondent systolic BP pre- and posthypertension exercise $(n=30)$

\begin{tabular}{llllll}
\hline Variable & Group & Mean & SD & p-value & $\mathrm{n}$ \\
\hline Systolic & Intervention (Pre post) & $139(125.33)$ & $9.23(10.52)$ & 0.02 & 30 \\
& Control (Pre post) & $135.67(135.17)$ & $10.06(11.33)$ & 0.81 & 30 \\
\hline
\end{tabular}
BP: Blood pressure.

Based on Table 5, it showed that the mean decrease in systolic BP in respondents who did exercise was $13.67 \mathrm{mmHg}$ with standard deviation of 10.57 , while the mean decrease in systolic BP in respondents

Table 4: BP among respondent before and after hypertension exercise

\begin{tabular}{|c|c|c|c|c|c|c|}
\hline Variable & Intervention & & & Control & & \\
\hline$\overline{\text { Diastolic }}$ & Mean ranks & $z$ & $\mathrm{p}$ & Mean ranks & z & $\mathrm{p}$ \\
\hline Pre post & $6.00(13)$ & -4.002 & 0.000 & $7.33(7.55)$ & 1.976 & 0.048 \\
\hline
\end{tabular}

who did not exercise was $0.50 \mathrm{mmHg}$ with standard deviation 11.17, with value of $0.000(0<0.05)$, this means that hypertension exercise can lower systolic BP.

Table 5: Mean decreasing of BP among of intervention and control group after hypertension exercise

\begin{tabular}{lllll}
\hline Variable & Mean & SD & $\mathrm{n}$ & $\mathrm{p}$-value \\
\hline Systolic & & & & \\
$\quad$ Intervention & 13.67 & 10.57 & 30 & 0.000 \\
$\quad$ Control & -0.50 & 11.17 & 30 & 0.000 \\
\hline
\end{tabular}

Based on Table 6, it showed that the mean ranks decreased in diastolic $B P$ in respondents who did exercise was 40.95 with $Z$ value of -4.896 while the group who did not exercise hypertension decreased diastolic BP with mean ranks of 20.05 for respondents who did not exercise with the mean ranks with $p=0.000$.

Table 6: Mean decreasing diastolic BP among intervention group and control group

\begin{tabular}{lllll}
\hline Variabel & Mean Ranks & $\mathrm{Z}$ & $\mathrm{n}$ & $\mathrm{p}$-value \\
\hline Diastolic & & & & \\
$\quad$ Intervention & 40.95 & - & 30 & 0.000 \\
$\quad$ Control & 20.05 & 4.896 & 30 & \\
\hline BP: Blood pressure. & & & &
\end{tabular}

\section{Discussion}

Characteristics of the majority of respondents were female in the intervention group, whereas in the control group, the majority were male. Most respondents have junior high school education in the intervention group experienced hypertension for $<1$ years as well as more than half of the control group respondents also experienced hypertension for $<1$ year.

The results of this study indicate that hypertension exercise can significantly reduce the BP of hypertensive patients, which can reduce systolic BP with $p=0.000$, and it can also reduce diastolic BP with $p=0.017$, this is with other studies, namely, the effect aerobic exercise on hypertension among adult people and elderly [10]. This studies show that exercise is an adjuvant therapy in the management of hypertension [10], [11], [12].
This research is line with other research that exercise can control BP has been shown to be an effective and integral component of nonpharmacological interventions for BP control [13]. It is also in line with other studies that the training exercise program significantly reduced the systolic and diastolic outpatient day time BP by $6 \pm 12$ and $3 \pm 7 \mathrm{~mm} \mathrm{Hg}$, respectively $(p=0.03)$. Regular exercise reduces BP during activity and improves physical performance as assessed by maximal oxygen uptake and lactate level. Physical exercise can lower BP [14].

This is also in line with other studies that hypertension exercise can reduce BP in the elderly and hypertension exercise can be used as one of the independent interventions to the lower BP [12], [13]. This research is that supports this research is the other studies The intradialitic exercise can reduce systolic BP with p-value of 0.002 and can reduce diastolic BP in patients undergoing hemodialysis with $p$-value of 0.014 [15], [16], [17].

Hypertension exercise is a sport, one of which aims to increase blood flow and oxygen supply to the active muscles and skeleton, especially for the heart muscle. By exercising or exercising, the need for oxygen in the cells will increase for the energy formation process, resulting in an increase in the heart rate so that cardiac output and stroke volume increases [18]. Thus, the BP will increase. After resting, the blood vessels will dilate or stretch and the blood flow will drop temporarily, about 30-130 min later it will return to the $\mathrm{BP}$ before exercise. If you do exercise regularelly and continuously, the decrease in BP will last longer and the blood vessels will be more elastic. The mechanism of lowering BP after exercise is because exercise can relax blood vessels and BP will drop [19].

Exercise has an antihypertensive effect although not completely, exercise or exercise video can reduce vasoconstriction which is triggered by sympathetic nerve work and reduced catecholamine, increases insulin sensitivity, has anti-inflammatory effect, and increase structural adaptation of vascular [10].

\section{Conclusion}

Significantly hypertensive exercise reduces systolic and diastolic BP of hypertensive patients.

\section{Recommendation}

Encourage regular hypertension exercise for 30 min times a week to reduce BP of hypertensive patients. 


\section{References}

1. Gudsoorkar PP, Tobe SW. Changing concepts in hypertension management. J Hum Hypertens. 2017;57(31):763-7. https://doi. org/10.1038/jhh.2017.57

PMid:28748919

2. Materson BJ, Estrada MJ, Degraff SB, Preston RA. Prehypertension is real and can be associated with target organ damage. J Am Soc Hyperten. 2017;11(11):704-8. https://doi. org/10.1016/j.jash.2017.09.005

PMid:28965768

3. Ministry of Health. Basic Health Research, Research and Development Agency. India: Ministry of Health; 2018.

4. Liwa A, Roediger R, Jaka H, Bougaila A, Smart L, Langwick S, et al. Herbal and alternative medicine use in Tanzanian adults admitted with hypertension-related diseases: A mixed-methods study. Int J Hypertens. 2017;20(17):569-72. https://doi. org/10.1155/2017/5692572

PMid:28634545

5. Bisognano JD, Basile JN. From the president, American society of hypertension. J Am Soc Hyperten. 2017;11(11):697-778.

PMid:29054402

6. Beune JA, Mollyan CP, Leo B, Jacob M, Charles OA. Culturally adapted hypertension education (CAHE) to improve blood pressure control and treatment adherence in patients of African origin with uncontrolled hypertension: Cluster-randomized trial. PLoS One. 2014;9(3):e90103. https://doi.org/10.1371/journal. pone.0090103

PMid:24598584

7. Murakami K. Home blood pressure predicts stroke incidence among older adults with impaired physical function: The Ohasama study. J Hypertens. 2017;35(12):2395-401. https:// doi.org/10.1097/hjh.0000000000001473 PMid:28697009

8. Reddy KS, Katan MB. Diet, nutrition and the prevention of hypertension and cardiovascular diseases. Public Health Nutr. 2016;7(1A):167-86. https://doi.org/10.1079/phn2003587 PMid:14972059

9. Rezky RA. Effect of foot reflexology therapy on blood pressure in patients with primary hypertension. JOM. 2015;2(2):124-30. PMid:15502439

10. Pedersen BK, Saltin B. Exercise as medicine-evidence for prescribing exercise as therapy in 26 different chronic disease. Scand J Med Sci Sports. 2015;25(3):1-72. https://doi. org/10.1111/sms.12581

PMid:26606383

11. Anwari M, Vidyawati $R$, Salamah $R$, Refani MA, Winingsih $N$ Inna $\mathrm{R}$, et al. Eye movement exercises for eye health: Case study on assisted families in Kemuningsari Lor village, Panti District, Jember. Indones J Health Sci. 2018;155-159. https:// doi.org/10.32528/ijhs.v0i0.1540

12. Margaret S, Monica O, Anna A, Laurie W, Thomas M. Heart of hypertension project: Development of a community-based prevention program for young African American men. Prog Community Health Partnersh. 2013;7(2):163-9. https://doi. org/10.1353/cpr.2013.0022

PMid:23793247

13. Sabbahi A, Arena R, Elokda A, Phillips SA. Exercise and hypertension: Uncovering the mechanisme of vascular control. Prog Cardiovasc Dis. 2016;59(3):226-34. https://doi. org/10.1016/j.pcad.2016.09.006

PMid:27697533

14. Dimeo F, Pagonas N, Eibert F, Arndt R, Zidek W, Timm HW. Aerobic exercise reduces blood pressure in resistant hypertension. Hypertension. 2012;60(3):653-8. https://doi. org/10.1161/hypertensionaha.112.197780

PMid:22802220

15. Soliman HM. Effect if intradialytic exercise on fatigue, electrolytes level and blood pressure in hemodialisis patients: A randomized trial. J Nurs Educ Pract. 2015;5(11):16. https:// doi.org/10.5430/jnep.v5n11p16

16. Harmilah RA, Induniasih KF. Intradialitic Exercise Maintain Vital Sign and Improve The Quality of Hemodialist Patients; 2019. [Last accessed on 2021 June 10]. Available from: http://www. eprints.poltekkesjogja.ac.id.

17. Jose S, Devi B, Victoria E. Effectivenees of intradialitic leg exercise (ILE) on fatigue and activities of daily living among patients subjected to hemodialisis. J Sci. 2014;4(1):13-8.

18. Qiu Z, Zheng K, Zhang H, Feng JJ, Wang L, Zhou H. Physical exercise and patients with chronic renal failure: A meta-analysis. BioMed Res Int. 2017;2017:8. https://doi. org/10.1155/2017/7191826

19. Inder JD, Carlson DJ, Dieberg G, McFarlane JR, Hess NC, Smart NA. Isometric exercise training for blood pressure management: A systematic review and meta-analysis to optimize benefit. Hypertens Res. 2016;39(2):88-94. https://doi. org/10.1038/hr.2015.111

PMid:26467494 